\title{
Isolation of Calcospherulites from the Mineralization Front of Bone
}

\author{
Ronald J. Midura ${ }^{\mathrm{a}}$ Amit Vasanji $^{\mathrm{a}}$ Xiaowei Su$^{\mathrm{a}}$ Sharon B. Midura ${ }^{\mathrm{a}}$ \\ Jeff P. Gorski ${ }^{\text {b }}$ \\ ${ }^{a}$ Department of Biomedical Engineering and Orthopaedic Research Center, Lerner Research Institute, \\ Cleveland Clinic, Cleveland, Ohio, and ${ }^{\mathrm{b}}$ Department of Oral Biology, School of Dentistry, University of Missouri \\ at Kansas City, Kansas City, Mo., USA
}

\section{Key Words}

Bone formation - Mineralization front · Calcospherulites • Biomineralization $\cdot$ Bone matrix proteins

\begin{abstract}
Calcium-containing spherical bodies (calcospherulites) exist along the mineralization front of bone and are thought to play a role in bone formation. Existing methods to isolate calcospherulites involve harsh treatments that remove much of their organic matter. This study sought to isolate them using a less destructive approach to better preserve their organic components. Juvenile rats were injected with a low dose of calcein to label the newly formed mineral at the mineralization front of bone in vivo. Periosteum was completely dissected from the tibial diaphysis and unmineralized osteoid matrix was removed by collagenase in order to expose calcospherulites. Calcein-labeled calcospherulites of approximately $0.5 \mu \mathrm{m}$ average diameter were observed all along the mineralization front and they exhibited a $\mathrm{Ca} / \mathrm{P}$ ratio of 1.3 in situ. Calcospherulites were released from the mineralization front by a short dispase digestion and isolated via fluorescence flow sorting. X-ray diffraction revealed they contained apatite crystals (c-axis length of $17.5 \pm 0.2$ $\mathrm{nm}$ ) and their $\mathrm{Ca} / \mathrm{P}$ ratio was preserved during isolation. Calcospherulites treated with ice-cold ethanol exhibited a $\mathrm{Ca} / \mathrm{P}$ ratio of 1.6, suggesting the presence of some extractable phospholipids. Proteins extracted from isolated calcospher-
\end{abstract}

ulites were resolved by SDS-PAGE into more than 20 distinct bands. Western blot analyses showed the presence of matrix proteins in these preparations. These results indicate that calcospherulites can be isolated from the mineralization front of bone in a form that can be used to study their proteome and lipid composition. Copyright $\odot 2008 \mathrm{~S}$. Karger AG, Basel

\section{Introduction}

The mineralization front of bone is central to an understanding of the physiological process of bone formation, as it represents the dynamic interface between poorly and fully mineralized osteoid. Prior studies have reported the presence of calcified, spherical- or fusiform-shaped structures (calcospherulites) all along the mineralization front of bone [Boyde and Sela, 1978; Sela and Bab, 1979; Ornoy et al., 1980; Aaron et al., 1999]. It has been reported that calcospherulites cluster together during periods of rapid bone formation, and that this focal aggregation is defined by an extracellular matrix as-

\section{Abbreviation used in this paper}

EDS energy dispersive spectroscopy

\section{KARGER}

Fax +4161306 1234

E-Mail karger@karger.ch

www.karger.com (c) 2008 S. Karger AG, Basel

$1422-6405 / 09 / 1894-0075 \$ 26.00 / 0$

Accessible online at:

www.karger.com/cto
Dr. Ronald J. Midura

Department of Biomedical Engineering-ND20, Cleveland Clinic 9500 Euclid Ave.

Cleveland, Ohio 44195 (USA)

Tel. +1 216445 3212, Fax +1 216444 9198, E-Mail midurar@ccf.org 
sembly of bone acidic glycoprotein-75 [Gorski et al., 2004; Midura et al., 2004]. Another bone matrix protein associated with calcospherulites is bone sialoprotein, which has been shown to nucleate apatite crystals in vitro [Hunter and Goldberg, 1993]. Calcospherulites may represent an aggregate of mature, well-mineralized matrix vesicles, though it is not known how this occurs. This uncertainty stems, in part, from the lack of a method to release and recover calcospherulites with much of their organic matter intact [Boyde and Sela, 1978; Sela and Bab, 1979; Ornoy et al., 1980; Aaron et al., 1999]. This study's objective was to develop a means to isolate calcospherulites from the mineralization front of bone in a manner that would preserve their inorganic and organic constituents.

\section{Materials and Methods}

All reagents used in this study were of the highest purity commercially available. Materials, antibodies and experimental procedures have already been described in detail [Midura et al., 2007]. Male Sprague Dawley rats (approx. $45 \mathrm{~g}$ body weight) were injected using a single intraperitoneal delivery of $10 \mu \mathrm{g} / \mathrm{g}$ body weight of calcein in phosphate-buffered saline, $\mathrm{pH} 7.4$, and allowed free cage activity for a 24 -hour period after calcein injection. Seven-millimeter-long tibial diaphysis segments were obtained and periosteum was removed by dissection. Exposed unmineralized osteoid matrix on the periosteal surface of waxplugged diaphyses was removed using type I collagenase (Boehringer Mannheim, Mannheim, Germany) digestion $(0.5 \mathrm{mg} / \mathrm{ml})$ in Hank's balanced salt solution plus the serine protease inhibitor 4-(2-aminoethyl)-benzene sulfonyl fluoride at $1 \mathrm{~mm}$ for $16 \mathrm{~h}$ at $37^{\circ} \mathrm{C}$. Exposed calcospherulites were removed by dispase digestion using $6 \mathrm{U} / \mathrm{ml}$ dispase (Boehringer Mannheim) for $30 \mathrm{~min}$ at $37^{\circ} \mathrm{C}$ in Tris-buffered saline, $\mathrm{pH}$ 7.6. Dispase digests were submitted to low-speed centrifugation (100 $\mathrm{g}$ for $5 \mathrm{~min}$ ) to remove any large aggregates and partially digested matrix, and then to highspeed centrifugation $(30,000 \mathrm{~g}$ for $20 \mathrm{~min}$ ) to isolate calcospherulites.

For fluorescence flow sorting, high-speed pellets were resuspended in a solution of $1 \%$ bovine serum albumin (Fraction V; Sigma, St. Louis, Mo., USA) in phosphate-buffered saline, and then transferred to analysis tubes (Falcon 352058). Resuspended calcospherulites were then analyzed for the presence of calcein labeling by FACS analysis using a 488-nm excitation line from an argon laser (FACScan; Becton Dickinson, San Jose, Calif., USA). The sorter was gated to count particles smaller than $3 \mu \mathrm{m}$ using Polybead Dyed Yellow 3.0 microspheres (No. 17139; Polyscience Inc., Warrington, Pa., USA). Isolated calcospherulites were spotted onto Formvar-coated, carbon-reinforced copper grids for evaluation in a Philips CM 20 transmission electron microscope operating at $100 \mathrm{kV}$.

Some collagenase-digested bone specimens were coated with palladium and examined with a Hitachi-S4500 FEG scanning electron microscope. The accelerating voltage was $5 \mathrm{kV}$ for imaging and $10 \mathrm{kV}$ for energy dispersive spectroscopy (EDS) analysis.
Diffraction patterns were recorded with a Rigaku X-ray diffractometer equipped with a graphite monochromator calibrated to $\mathrm{CuK} \alpha$ radiation $(\lambda=0.154 \mathrm{~nm})$ and with a scintillation counter detector coupled to a linear ratemeter for data collection. All sample data were compared to a reference standard of well-crystallized hydroxyapatite as previously described [Midura et al., 2007].

Other calcospherulite preparations were resuspended in a solution of 4 M guanidine $\mathrm{HCl}, 0.4$ M EDTA, 2\% Triton X-100, 100 $\mathrm{mm}$ 6-aminohexanoic acid, $10 \mathrm{~mm}$ N-ethylmaleimide, $1 \mathrm{~mm}$ phenylmethylsulfonyl fluoride, $5 \mathrm{~mm}$ benzamidine $\mathrm{HCl}, 50 \mathrm{mM}$ sodium acetate, $\mathrm{pH} 5.8$, with mixing for $24 \mathrm{~h}$ at $4^{\circ} \mathrm{C}$. Recovered extraction solutions $(0.5 \mathrm{ml}$ volume) were desalted on Sephadex G-50 columns $(7 \times 80 \mathrm{~mm})$ eluted with $10 \mathrm{M}$ formamide, $1 \%$ CHAPS, $150 \mathrm{~mm} \mathrm{NaCl}$ and $50 \mathrm{~mm}$ sodium acetate, $\mathrm{pH}$ 5.8. Void volume samples were concentrated on Microcon YM-3 centrifugal filter devices (Millipore Corp., Bedford, Mass., USA) and then mixed with an equal volume of $2 \times$ SDS sample buffer. Protein contents were measured by Pierce Micro BCA protein assay kit (Pierce Biotechnology Inc., Rockford, Ill., USA). Two micrograms of concentrated protein from each sample was applied in a total of $12 \mu \mathrm{l}$ volume to each lane in SDS-polyacrylamide linear 4-20\% gradient minigels using the Laemmli buffer system $(1 \mathrm{~mm}$ width, 12 wells, EC60252; Invitrogen, Carlsbad, Calif., USA). Gels were run at $125 \mathrm{~V}$ for $2 \mathrm{~h}$. Some gels were stained with Sypro Tangerine Orange Protein Gel Stain (S-12010; Molecular Probes, Eugene, Oreg., USA) to view protein-banding patterns, while other gels were transferred to Immobilon-P membranes (IPVH10100; Millipore Corp.) in a wet blot module at $30 \mathrm{~V}$ for $5 \mathrm{~h}$. Western blot analyses were done following blocking overnight in $5 \%$ ovalbumin in Tris-buffered saline. Primary (1:1,000 dilution) and secondary (1:15,000 dilution) antibodies were diluted into $0.1 \%$ ovalbumin in Tris-buffered saline, and exposed to the blot membrane overnight at $4^{\circ} \mathrm{C}$ and for $2 \mathrm{~h}$ at room temperature, respectively. Positive signals were detected using ECL Plus Western blotting detection system (GE Healthcare Bio-Sciences Corp., Piscataway, N.J., USA).

\section{Results}

The mineralization front of bone is readily apparent in undecalcified sections of juvenile rat tibial diaphysis stained with toluidine blue, and dark spherulites were observed all along the mineralization front (fig. 1a, b), having an average diameter of $0.56 \pm 0.38 \mu \mathrm{m}$. Epifluorescence confocal microscopy revealed a calcein-labeled layer along the periosteal mineralization front, which appeared to be replete with calcein-labeled calcospherulites (fig. 1c) having an average diameter of $0.49 \pm 0.31 \mu \mathrm{m}$.

Periosteal cell layers were dissected from tibial diaphyses in order to expose the underlying osteoid matrix layer [Midura et al., 2007]. Osteoid matrix consists in large part of unmineralized and poorly mineralized type I collagen fibers. Accordingly, highly purified collagenase was used to remove the unmineralized matrix and expose the underlying mineralization front. Images of the mineral- 

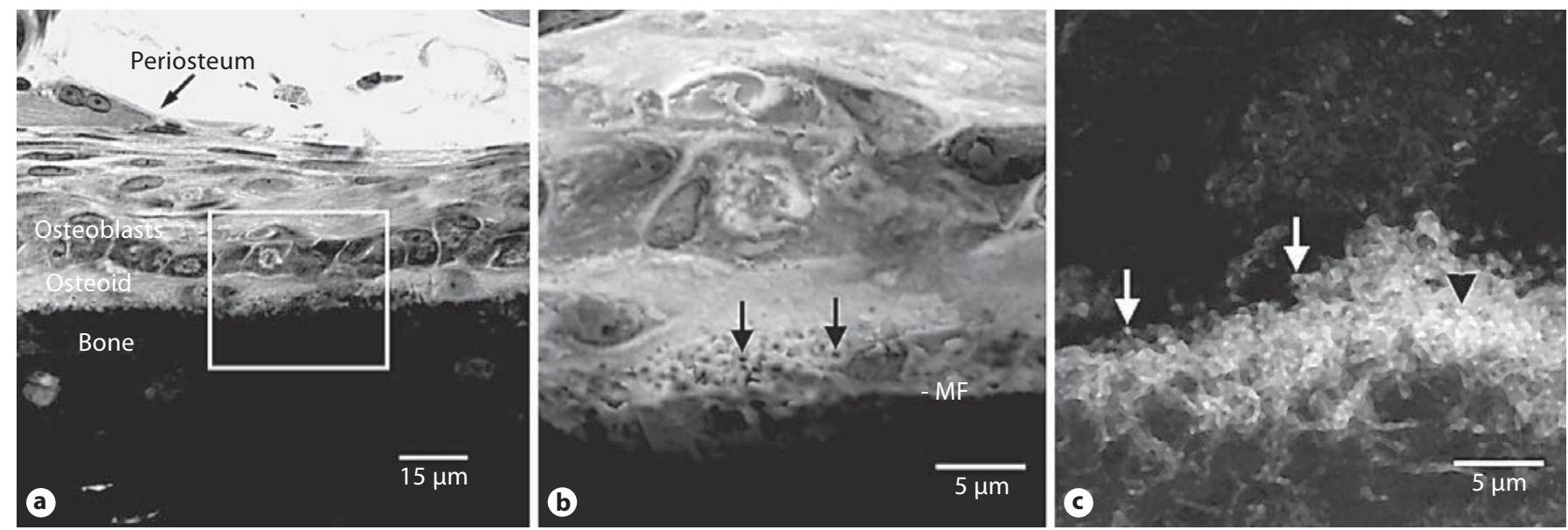

Fig. 1. Calcospherulites along the mineralization front of bone. a Transmission mode confocal microscopy images of a toluidine blue-stained undecalcified section of tibial diaphysis tissue from a juvenile rat. Periosteum, osteoblasts, osteoid and bone locations are noted. The box identifies a region of interest at the mineralization front that is shown at higher magnification in $\mathbf{b}$. $\mathbf{b}$ Location of the mineralization front (MF) is indicated. The black arrows point to the calcospherulites referred to in the text. c Epifluorescence confocal microscopy image of the periosteal mineralization front labeled in vivo with calcein. Locations are indicated for calcein-labeled spherulites at (white arrows) or within (black arrowhead) the mineralization front. ization front showed numerous calcospherulites (fig. 2), exhibiting an overall average diameter of $0.47 \pm 0.22$ $\mu \mathrm{m}$. Some calcospherulites appeared to have smaller spherical structures (approx. $100 \mathrm{~nm}$ diameter) attached to their outer surfaces (fig. 2b). Images also revealed the presence of 80-nm-thick fibers within the matrix spaces between calcospherulites (fig. 2b). EDS analysis of calcospherulites in situ revealed an average $\mathrm{Ca} / \mathrm{P}$ ratio of 1.3 . Other specimens were subsequently treated with dispase to digest these collagenase-resistant molecules and release calcospherulites from the mineralization front. This quantitatively removed calcospherulites from the mineralization front and revealed overlapping plate-like structures yielding an average $\mathrm{Ca} / \mathrm{P}$ ratio of 1.7 [Midura et al., 2007].

Calcospherulites released from the mineralization front of bone were isolated by fluorescence sorting and centrifugation, and then confirmed to exist as individual spherulites of approximately $0.5 \mu \mathrm{m}$ diameter via wholemount transmission electron microscopy (fig. 3). EDS

Fig. 2. Collagenase digestion reveals abundant calcospherulites. Shown are scanning electron micrographs at two magnifications. The prevalence of calcospherulites (a) and calcospherulites in proximity to 80 -nm-thick fibers (b) are shown. The white arrow points to a calcospherulite while the white arrowhead points to a fiber.

Isolation of Calcospherulites from the Mineralization Front of Bone

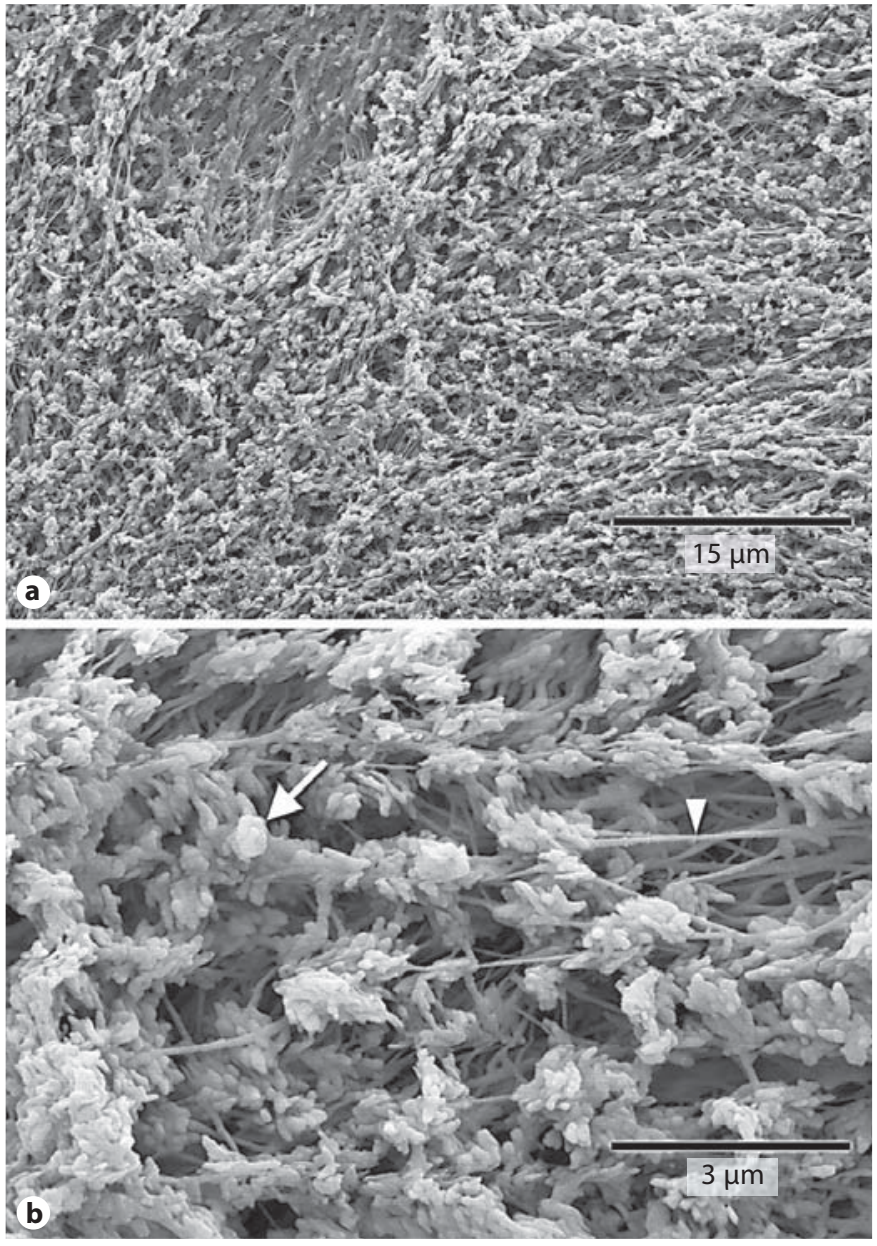

Cells Tissues Organs 2009;189:75-79 


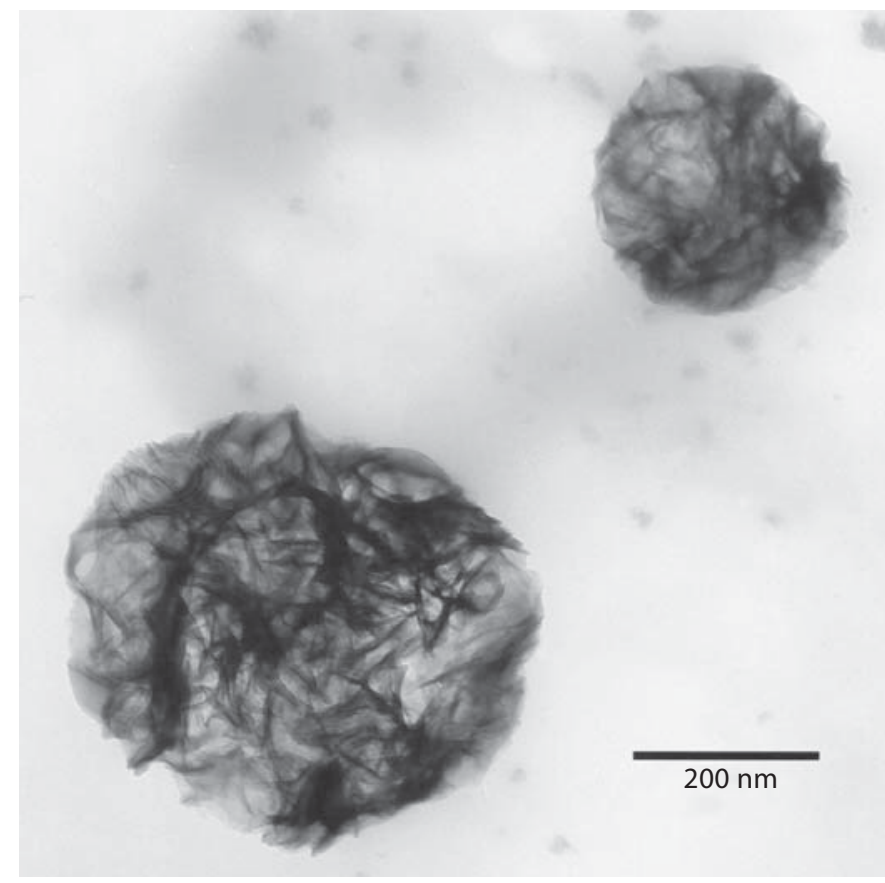

Fig. 3. Calcospherulites released by dispase digestion and isolated by fluorescence flow sorting. Shown is a transmission electron micrograph containing 2 calcospherulites isolated by calcein fluorescence sorting, recovered by centrifugation and spotted onto carbon-coated copper grids (native contrast).

analysis revealed these isolated calcospherulites had a $\mathrm{Ca} / \mathrm{P}$ ratio of $1.3 \pm 0.1$. X-ray diffraction analysis demonstrated that isolated calcospherulites contained a poorly crystalline apatite mineral phase having an average c-axis crystal length that was calculated to be $17.5 \pm 0.2$ $\mathrm{nm}$ [Midura et al., 2007].

$\mathrm{The} \mathrm{Ca} / \mathrm{P}$ ratio of these isolated calcospherulites was less than the theoretical value expected for pure hydroxyapatite, suggesting the presence of phospholipids and/or phosphoproteins. Calcospherulites attached to electron microscopy grids were treated with ice-cold $70 \%$ ethanol in order to selectively remove phospholipids [Lee et al., 1998], and resubmitted to EDS analysis. This elevated the $\mathrm{Ca} / \mathrm{P}$ ratio to $1.6 \pm 0.1$, indicating the presence of ethanol-extractable phosphorus in isolated calcospherulites and suggesting that phospholipids are likely to be associated with calcospherulites.

Protein extracts from isolated calcospherulites exhibited 4 prominent bands $(240,120,80$ and $55 \mathrm{kDa})$ and several relatively lower intensity bands when analyzed by one-dimensional SDS-PAGE (fig. 4). Western blot analysis revealed the presence of bone matrix phosphoproteins

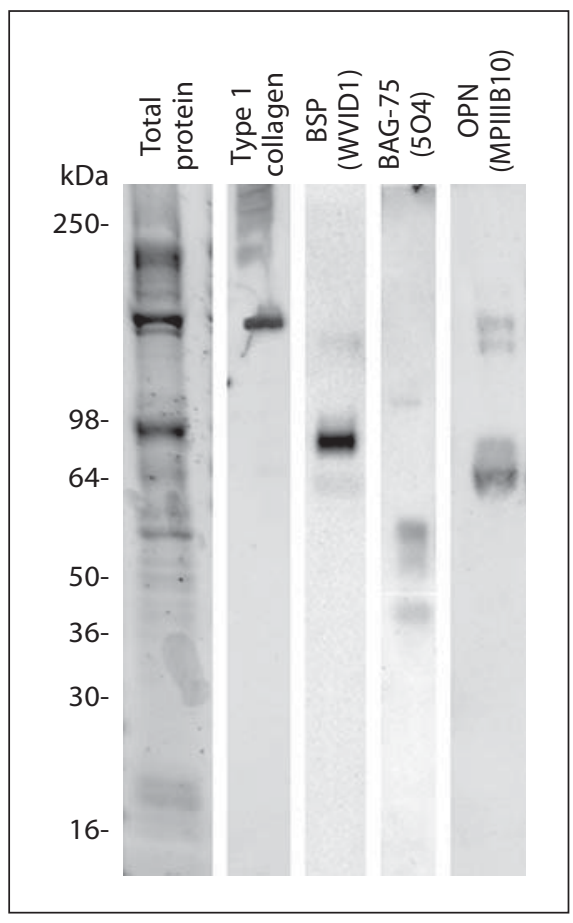

Fig. 4. Western blot analysis of bone matrix proteins extracted from isolated calcospherulites. See-Blue molecular weight marker locations are indicated on the left. Western signal for mature type I collagen is observed at approximately $120 \mathrm{kDa}$, while the higher molecular weight bands represent partially processed procollagen molecules. Western signals for mature bone sialoprotein (BSP, $75 \mathrm{kDa}$ ), bone acidic glycoprotein-75 (BAG-75, $57 \mathrm{kDa}$ ) and osteopontin $(\mathrm{OPN}, 66 \mathrm{kDa})$ are observed.

(bone sialoprotein, osteopontin and bone acidic glycoprotein-75) as well as both mature and partially processed type I collagen $\alpha$-chains (fig. 4 ).

\section{Discussion}

Several groups have reported the presence of discrete spherical- or fusiform-shaped entities at the mineralization front of bone having similar structural and elemental characteristics to what is described herein [Boyde and Sela, 1978; Sela and Bab, 1979; Ornoy et al., 1980; Aaron et al., 1999; Gorski et al., 2004; Midura et al., 2004]. The unique contribution of the present study is the development of a procedure to isolate calcospherulites with a better preserved organic composition than previously reported. Further, this study provides an initial biochemical characterization of calcospherulites demonstrating the presence of extracellular matrix proteins. With this 
calcospherulite isolation method in place, we are now poised to investigate the proteomics of their structural and functional attributes. Nevertheless, a complete proteome of calcospherulites will require other less destructive methods of isolation than described herein because the proteolytic activity of dispase likely degraded proteins and any proteoglycans associated with the calcospherulites that were not protected by the mineral salts or lipids.

It has been previously suggested that matrix vesicles may aggregate and transition to become calcospherulites [Sela and Bab, 1979; Ornoy et al., 1980]. Our data revealed the presence of ethanol-extractable phosphorus from iso- lated calcospherulites, and future studies will reveal the nature of this extractable phosphorus. Since polynucleotides, polypeptides and polysaccharides are insoluble in cold ethanol, the most likely explanation for this ethanolextractable phosphorus would be phospholipids [Lee et al., 1998]. If this is true, an apparent association of phospholipids with calcospherulites would be consistent with the concept that some type of matrix vesicle aggregation phenomenon could contribute some of their contents to become calcospherulites. The presence of some 100-nm diameter spherical structures aggregating on the surface of calcospherulites in figure 2 is evidence consistent with this hypothesis.

\section{References}

Aaron, J.E., B. Oliver, N. Clarke, D.H. Carter (1999) Calcified microspheres as biological entities and their isolation from bone. Histochem J 31: 455-470.

Boyde, A., J. Sela (1978) Scanning electron microscope study of separated calcospherites from the matrices of different mineralizing systems. Calcif Tissue Res 26: 47-49.

Gorski, J.P., A. Wang, D. Lovitch, D. Law, K. Powell, R.J. Midura (2004) Extracellular bone acidic glycoprotein-75 defines condensed mesenchyme regions to be mineralized and localizes with bone sialoprotein during intramembranous bone formation. J Biol Chem 279: 25455-25463.
Hunter, G.K., H.A. Goldberg (1993) Nucleation of hydroxyapatite by bone sialoprotein. Proc Natl Acad Sci USA 90: 8562-8565.

Lee, C.-H., N. Vyavahare, R. Zand, H. Kruth, F. J. Schoen, R. Bianco, R.J. Levy (1998) Inhibition of aortic wall calcification in bioprosthetic heart valves by ethanol pretreatment: biochemical and biophysical mechanisms. J Biomed Mater Res 42: 30-37.

Midura, R.J., A. Vasanji, X. Su, A. Wang, S.B. Midura, J.P. Gorski (2007) Calcospherulites isolated from the mineralization front of bone induce the mineralization of type I collagen. Bone 41: 1005-1016.
Midura, R.J., A. Wang, D. Lovitch, D. Law, K. Powell, J.P. Gorski (2004) Bone acidic glycoprotein-75 delineates the extracellular sites of future bone sialoprotein accumulation and apatite nucleation in osteoblastic cultures. J Biol Chem 279: 25464-25472.

Ornoy, A., I. Atkin, J. Levy (1980) Ultrastructural studies on the origin and structure of matrix vesicles in bone of young rats. Acta Anat 106: 450-461.

Sela, J., I.A. Bab (1979) Correlative transmission and scanning electron microscopy of the initial mineralization of healing alveolar bone in rats. Acta Anat 105: 401-408. 